\title{
Decreased number of deaths related to severe traumatic brain injury in intensive care unit during the first lockdown in Normandy: at least one positive side effect of the COVID-19 pandemic
}

\author{
Frederick Rault ${ }^{1}$ (1) $\cdot$ Laura Terrier $^{2} \cdot$ Arthur Leclerc $^{1} \cdot$ Vianney Gilard $^{2,3} \cdot$ Evelyne Emery $^{1,4,5} \cdot$ Stéphane Derrey $^{2}$. \\ Anaïs R. Briant ${ }^{6}$. Clément Gakuba ${ }^{4,5,7}$. Thomas Gaberel ${ }^{1,4,5}$
}

Received: 6 February 2021 / Accepted: 23 March 2021 / Published online: 4 April 2021

(C) The Author(s), under exclusive licence to Springer-Verlag GmbH Austria, part of Springer Nature 2021

\begin{abstract}
Background The COVID-19 pandemic has led to severe containment measures to protect the population in France. The first lockdown modified daily living and could have led to a decrease in the frequency of severe traumatic brain injury (TBI). In the present study, we compared the frequency and severity of severe TBI before and during the first containment in Normandy. Methods We included all patients admitted in the intensive care unit (ICU) for severe TBI in the two tertiary neurosurgical trauma centres of Normandy during the first lockdown. The year before the containment served as control. The primary outcome was the number of patients admitted per week in ICU. We compared the demographic characteristics, TBI mechanisms, CT scan, surgical procedure, and mortality rate.

Results The incidence of admissions for severe TBI in Normandy decreased by 33\% during the containment. The aetiology of TBI significantly changed during the containment: there were less traffic road accidents and more TBI related to alcohol consumption. Patients with severe TBI during the containment had a better prognosis according to the impact score $(p=0.04)$. We observed a significant decrease in the rate of short-term mortality related to severe TBI during the period of lockdown $(p=0.02)$.

Conclusions Containment related to the COVID-19 pandemic has resulted in a modification of the mechanisms of severe TBI in Normandy, which was associated with a decline in the rate of short-term death in intensive unit care.
\end{abstract}

Keywords COVID-19 $\cdot$ Traumatic brain injury $\cdot$ Lockdown $\cdot$ Intensive care unit $\cdot$ Outcome

\section{Introduction}

The outbreak of the COVID-19 virus began in Wuhan, China, in December 2019. Chinese authorities decided to quarantine their population to limit the spread of the virus. In France, the first wave began in spring 2020 [31]. From 1 March to 12

This article is part of the Topical Collection on Brain trauma

Frederick Rault

rault-f@chu-caen.fr

1 Department of Neurosurgery, Caen University Hospital, Avenue de la Côte de Nacre, 14000 Caen, France

2 Department of Neurosurgery, Rouen University Hospital, F-76000 Rouen, France
May, $>95,000$ patients with COVID-19 were hospitalized and $>25,000$ died in France [27]. Our government set up the first lockdown on March 17, which ended on May 11, 2020.

This containment combined two aspects. Firstly, an adaptation of the hospital policy, as 5\% of COVID-19 patients need hospitalization in intensive unit care (ICU) [32]. All

3 Laboratory of Microvascular Endothelium and Neonate Brain Lesions, Normandie Univ, UNIROUEN, INSERM U1245, F-76000 Rouen, France

4 PhIND "Physiopathology and Imaging of Neurological Disorders", Institut Blood and Brain @ Caen-Normandie, Normandie Univ, UNICAEN, INSERM, U1237, Cyceron, 14000 Caen, France

5 Medical School, Université Caen Normandie, F-14000 Caen, France

6 Unité de Biostatistique et Recherche Clinique (UBRC), Caen, France

7 Department of Anesthesiology and Critical Care Medicine, CHU de Caen, F-14000 Caen, France 
hospitals suspended all non-urgent interventions to keep places for COVID patients. Operative volume dropped more than $50 \%$ as reported by Walter et al. around the world [10]. We rescheduled surgery for degenerative spine, non-urgent brain tumour, and unruptured aneurysm like our colleagues in Strasbourg [4]. We have organized teleconsultation for the most vulnerable patients.

Secondly, the French population was confined to home. The Ministry of Education decided to close schools and universities. The government only authorized an opening for markets, pharmacies, banks, and gas stations. Employers had to develop telework in their society. These measures minimized trips and impacted the frequency of emergencies, especially traumatic injuries. In Paris, Pichard et al. observed a decrease of upper limb injuries by 65\% in their Orthopaedic Department [17]. The restriction of mobility theoretically reduces the exposure to traumatic brain injuries too (TBI). TBI is a public health problem: each year, there are about 150,000 new cases, with 4000 patients in a coma [13]. Moreover, severe TBI patients are hospitalized in ICU, like COVID patients.

The aim of the present study is to evaluate the impact of the first lockdown on frequency and severity for severe TBI admitted to ICU in Normandy.

\section{Methods}

We conducted a retrospective cohort study with data provided by the two tertiary neurosurgical units in Normandy: University Hospitals of Caen and Rouen. We included all consecutive patients admitted to the intensive care unit for severe TBI. These two hospitals are trauma centres and are the only ones to manage severe TBI in our region.

The inclusion periods for cases were the first 6 weeks of the containment (March 18 to April 28, 2020) and the 12 previous months for the control group (March 20, 2019, to March 17, 2020).

Patients were included in the study if they were admitted in ICU for a severe TBI, defined as a TBI with a Glasgow coma scale equal to or less than 8 , and age over 16 years old. We excluded chronic subdural hematomas from this study. The incidence of admission for severe TBI per week was calculated based on the population in Normandy, determined by the French National Institute for Statistics and Economic Research [20].

We registered on admission the patient's age, sex, neurological examination for each group. Emergencies physicians evaluated Glasgow coma score before sedation and intubation. We researched the mechanisms for each TBI, divided between domestic falls, road accidents, and others. The consumption of alcohol was reported and positive when the alcohol blood level was above $0.5 \mathrm{~g} / \mathrm{l}$ of blood on admission. We used Marshall's classification for the CT scan performed on admission [12].

We reported the type of surgical procedure: intracranial pressure (ICP) monitoring, external ventricular drainage (EVD) insertion, evacuation of an extradural hematoma $(\mathrm{EDH})$, acute subdural hematoma (SDH) evacuation, intracerebral hematoma ( $\mathrm{ICH})$ evacuation, and decompressive craniectomy (DC). To evaluate the prognosis of patients, we calculated the impact score [29].

We finally looked at early mortality related to TBI, defined as the number of deaths per week per centre within the first 2 weeks after the admission. The primary outcome was the number of TBI per week admitted in ICU.

Statistical analyses were conducted using the MannWhitney $U$ or $t$-test for continuous variable and the Fisher exact test and chi-square for categorical data. Normality was tested for the continuous variable with the Shapiro-Wilk test. Statistical significance was set to alpha risk $<0.05$.

The study was reviewed and approved by the Institutional Ethics Committee of Caen University Hospital (Caen, France). Data supporting the findings of this study are available from the corresponding authors upon reasonable request.

\section{Results}

\section{Number of TBI admitted in ICU per week}

During the control period, we included 147 patients corresponding to 2.72 patients admitted per week (Fig. 1). In comparison with this result, 11 patients, corresponding to 1.83 patients per week, were admitted during the lockdown period. Considering the total population in Normandy, we found an incidence per week of 0.06 (2.4 per month) admissions in ICU for severe TBI per 100,000 inhabitants during the lockdown and 0.08 (3.6 per month) during the control period, corresponding to a decrease of $33 \%$.

\section{Baseline characteristics}

The median age of patients between the two periods was similar. Concerning gender, the proportion of women doubled during the containment. The rate of secondary referrals did not change with the containment. The aetiology of TBI changed during the containment (Fig. 2): there were less traffic road accidents $(9.1 \%$ vs $41.4 \%)$ and the proportion of domestic fall increased by $34 \%$ ( $81.8 \%$ vs $47.4 \%$ ). There were 69 domestic falls ( 1.33 per week) during the control phase and 9 for the containment (1.5 per week), corresponding to an absolute increase of $11 \%$. Moreover, a significantly larger proportion of patients admitted in the second period were under influence of alcohol (Fig. 3). Concerning the impact score, the prognosis at 6 months was better for patients 
Fig. 1 Number of patients with severe TBI admitted per week during non-containment period compared with containment time. The Shapiro-Wilk test was used but the data did not follow a normal distribution. The Wilcoxon Mann-Whitney was used to compare the two groups. We did not find any statistically difference with a $p$ value at 0.14

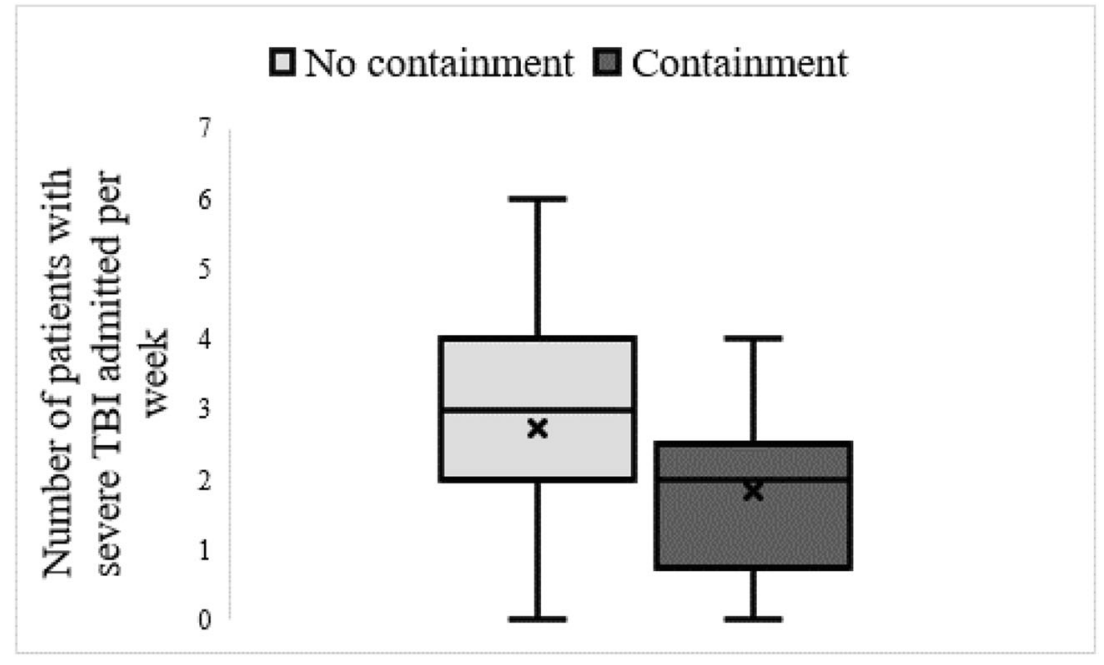

admitted during lockdown ( $p=0.04$; Table 1). For Marshall's classification, the proportion of worst grade (3-4-5-6) appeared to be declining $(45.4 .8 \%$ vs $57.8 \%)$ during containment.

\section{Surgical procedures}

The proportion of patients requiring surgical evacuation of acute subdural hematomas tripled (Table 2). We found an incidence of $0.02 \mathrm{SDH}$ evacuation per week for the period of lockdown in comparison with 0.009 during the control period, corresponding to an increase of $122 \%$. The rates of EDH evacuation, ICH evacuation, decompressive craniectomy, EVD insertion, and ICP monitoring were similar between the two periods. Subsequently, we have compared the characteristics of the patients with subdural hematoma between the two periods (Table 3). No variables, including the age, the neurologic examination, the $\mathrm{CT}$ scan characteristics, or management, were significantly different between the two groups. We however noticed the same tendency observed in the overall analysis, with an increase in the rate of women suffering from SDH and a better prognosis with a better Glasgow coma score during the containment.

\section{Early mortality in the ICU}

We found a significant decrease in the mortality rate for the patients with severe TBI admitted to the ICU (Table 1). Indeed, no patient died during the lockdown in the 2 weeks after the admission.

\section{Discussion}

\section{Main results}

In this study, we demonstrated that the first lockdown had a positive impact on the rate of severe traumatic brain
Fig. 2 Etiology of TBI. Causes of severe TBI in percent during the year before the lockdown March 2019-March2020 compared to the 6 first week of the lockdown in March-April 2020. The change of aetiology is significant with a $p$ value at 0.03

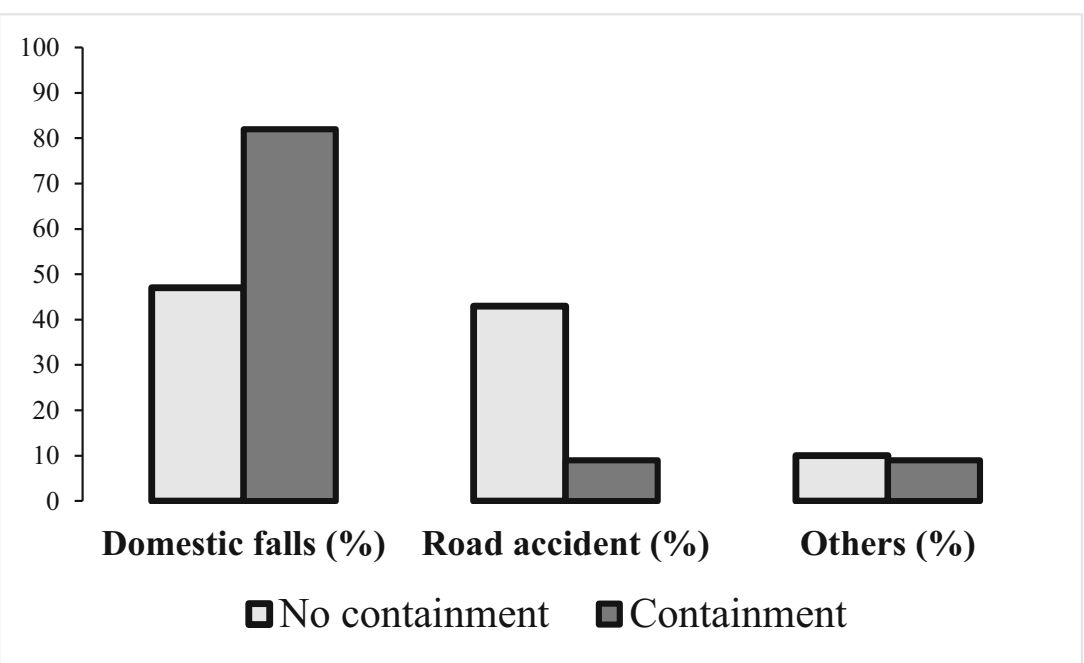


Fig. 3 Implication of alcohol consumption in TBI mechanisms. Comparison of the rate of TBI related to alcohol consumption during the COVID-19 containment period and before the containment period in Normandy, France

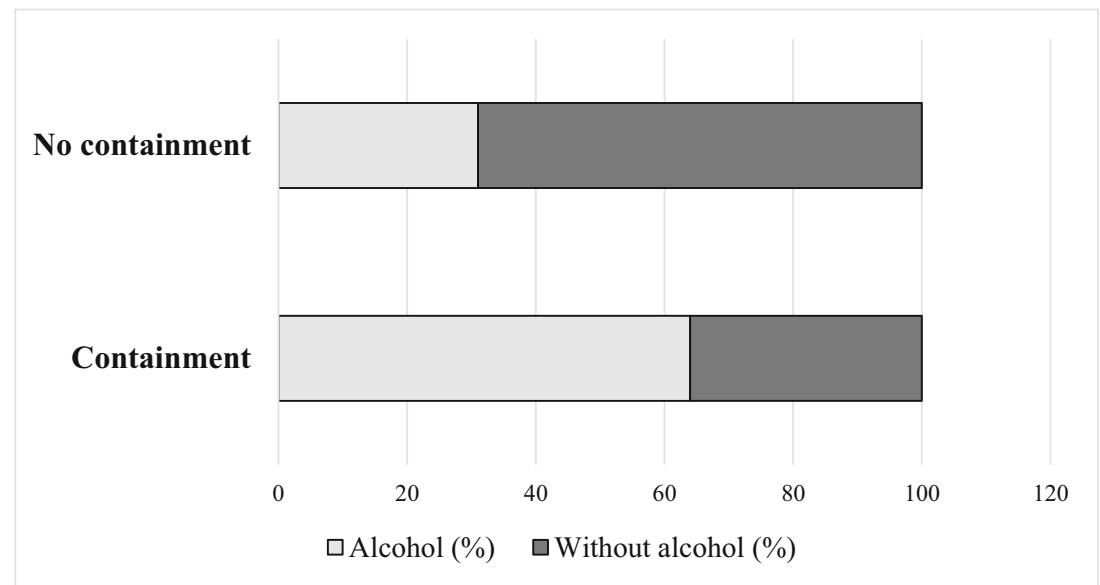

injuries in Normandy and has led to a decrease in the rate of short-term death after severe TBI. This decrease is related to two factors: (1) a decreasing number of severe TBI admitted to our institutions during the containment period; (2) a modification of the mechanisms of TBI, mainly a decrease in the rate of traffic road accidents that are often at high energy and also an increase in the rate of severe TBI related to alcohol consumption. This may have modified the type of cerebral lesion, which is suggested by the change of the distribution of Marshall's classification and the impact score: there were probably more diffuse lesions that are the most severe before than during the containment. There was also more SDH surgery during the containment, which is of better prognosis than diffuse lesions.

\section{The decrease in the rate of TBI during the containment in the world}

It was the first time in France, in the modern era, that such drastic restrictions were applied to limit the spread of a virus. The compliance of the French population for containment measures decreased the number of TBI admitted to the ICU by $33 \%$. Our results are consistent with the literature. The study published by Mathiesen et al. [14] based on 25 neurosurgical departments in Europe showed a significant decrease of TBI in 18 ICU between December 2019 and March 2020. A decrease in the incidence of TBI admitted in ICU was observed: 3.6 vs 1.2 TBI patients/1,000,000/month. Our incidence was relatively similar with 3.6 vs 2.4 patients/ $1,000,000$ habitants per month admitted for severe TBI.
Table 1 Baseline characteristics and short-term outcomes

\begin{tabular}{|c|c|c|c|}
\hline & $\begin{array}{l}\text { No containment } \\
\text { ( } 52 \text { weeks; } n=147 \text { ) }\end{array}$ & $\begin{array}{l}\text { Containment } \\
\text { ( } 6 \text { weeks; } n=11 \text { ) }\end{array}$ & $p$ value \\
\hline Median age (IQR) & $49(36.5)$ & $51(6.5)$ & 0.41 \\
\hline Women, $n(\%)$ & $32(21.8)$ & $5(45.4)$ & 0.13 \\
\hline GCS initial, median (IQR) & $4(4)$ & $3(3.5)$ & 0.15 \\
\hline Secondary referrals, $n(\%)$ & $25(17)$ & $2(18.2)$ & 0.68 \\
\hline \multicolumn{4}{|l|}{ Marshall score, $n(\%) *$} \\
\hline 1 & $11(7.9)$ & $2(18.2)$ & \multirow[t]{6}{*}{0.32} \\
\hline 2 & $48(34.3)$ & $4(36.4)$ & \\
\hline $3-4$ & $26(18.6)$ & $1(9.1)$ & \\
\hline 5 & $32(22.8)$ & $4(36.3)$ & \\
\hline 6 & $23(16.4)$ & $0(0)$ & \\
\hline Impact score * & & & \\
\hline Bad prognosis at 6 months, median (\%) (IQR) & $66(33.3)$ & $48(24)$ & 0.04 \\
\hline Risk of mortality at 6 months, median (\%) (IQR) & $44(37)$ & $35(22)$ & 0.07 \\
\hline Mortality, $n(\%)$ & $51(34.7)$ & $0(0)$ & 0.02 \\
\hline
\end{tabular}

Comparison of the baseline characteristics for patients with severe TBI before and during the COVID-19 containment period in Normandy, France. IQR, interquartile range. * Missing data in the no containment group (6\%). Significant values in bold 
Table 2 Surgical procedure

\begin{tabular}{llll}
\hline & $\begin{array}{l}\text { No containment } \\
(52 \text { weeks; } n=147)\end{array}$ & $\begin{array}{l}\text { Containment } \\
(6 \text { weeks; } n=11)\end{array}$ & $p$ value \\
\hline Intracranial pressure monitoring, $n(\%)$ & $65(47.4)$ & $5(45.4)$ & 0.95 \\
External ventricular drain, $n(\%)$ & $15(10.9)$ & $2(18.2)$ & 0.32 \\
Decompressive craniectomy, $n(\%)$ & $14(10.2)$ & $1(9.1)$ & 1 \\
Extradural hematoma evacuation, $n(\%)$ & $10(7.3)$ & $0(0)$ & 1 \\
Subdural hematoma evacuation, $n(\%)$ & $15(10.9)$ & $4(36.4)$ & $\mathbf{0 . 0 3}$ \\
Intraparenchymatous hematoma evacuation, $(\%)$ & $7(5.1)$ & $0(0)$ & 1 \\
\hline
\end{tabular}

Comparison of the surgical procedure for patients with severe TBI before and during the COVID-19 containment period in Normandy, France. Significant values are in bold

The situation was the same in entire Europe. In the region of Tyrol, Austria, the number of TBI patients admitted during 3 weeks during the lockdown was compared to the number of patients admitted during the same period from 2016 to 2019 [19]. The study included 122 patients and demonstrated a significant decrease number of patients with TBI admitted during the quarantine period. Tyrol is a busy region in winter because of winter sports practise, which is frequently responsible for TBI. In the UK, in a single centre study, a $49 \%$ decrease in the number of patients admitted for TBI was noticed, by comparing January to a period between January and May [9]. This massive difference is surprising because the government in the UK imposed a less strict containment than the one imposed in France. On the other hand, our colleagues in Helsinki [11] did not find the same result: in comparison with 2019, the number of admissions for TBI did not decrease. Outside Europe, similar findings were reported. In the USA, Figueroa et al. compared the admissions for neurotrauma in March and April 2020 to the same months in 2016 to 2019. They noticed a $62 \%$ decrease in total neurotrauma consults in April 2020 after the lockdown began [5]. In South Africa, a decline of $25 \%$ of patient's admissions for TBI in Johannesburg was observed [30]. Globally, the lockdown applied all around the world led to a decrease in the number of patients with TBI as described in a recent review of the literature [24]. So, our data are not original at first sight, however, almost all these studies evaluated the total rate of TBI, whereas our study has focused on severe TBI. Moreover, our study
Table 3 Comparison of patients with severe traumatic brain injury with subdural hematoma (SDH) before and during the COVID-19 containment period in Normandy

\begin{tabular}{|c|c|c|c|}
\hline & $\begin{array}{l}\text { No containment } \\
(n=22)\end{array}$ & $\begin{array}{l}\text { Containment } \\
(n=4)\end{array}$ & $p$ value \\
\hline \multicolumn{4}{|l|}{ Baseline characteristics } \\
\hline Median age, years (IQR) & $57(48.5-74)$ & $50(48.5-53.75)$ & 0.6 \\
\hline Female sex, $n(\%)$ & $6(27.3)$ & $1(25)$ & 1 \\
\hline Severe dependence before the TBI, $n(\%)$ & $1(4.5)$ & $1(25)$ & 0.3 \\
\hline \multicolumn{4}{|l|}{ Clinical examination } \\
\hline Median GCS, 3-8 (IQR) & $3.5(3-6)$ & $6(5.5-6.25)$ & 0.18 \\
\hline Median motor GCS, 1-6 (IQR) & $1.5(1-3.5)$ & $4(3.75-4.25)$ & 0.07 \\
\hline \multicolumn{4}{|l|}{ Pupil's status } \\
\hline Myosis, n (\%) & $5(22.7)$ & $0(0)$ & 0.73 \\
\hline Unilateral mydriasis, $n(\%)$ & $13(59.1)$ & $4(100)$ & \\
\hline \multicolumn{3}{|l|}{ CT scan } & \\
\hline Median SDH maximal width (mm), (IQR) * & $16(11.5-19.5)$ & $20.5(17.75-23.25)$ & 0.31 \\
\hline Midline shift $(\mathrm{mm}),(\mathrm{IQR}) *$ & $9(7-17)$ & $19(17-20)$ & 0.13 \\
\hline \multicolumn{4}{|l|}{ Patient care } \\
\hline $\begin{array}{l}\text { Decision to stop the active care because of } \\
\text { a too severe state, } n(\%)\end{array}$ & $9(39.1)$ & $1(25)$ & 1 \\
\hline SDH evacuation, $n(\%)$ & $13(59.1)$ & $4(100)$ & 0.26 \\
\hline Decompressive craniectomy, $n(\%)$ & $5(22.7)$ & $0(0)$ & 0.55 \\
\hline
\end{tabular}

$G C S$, Glasgow score; IQR, interquartile range. *Missing data for containment group (13.6\%) 
provides an interesting description of the modification of the aetiology of the TBI because of the lockdown, and some interesting data dealing with the modifications of the outcomes.

From a larger point of view, not only the frequency of TBI were impacted by the COVID-19 pandemic: as described by our Italian colleagues [3], all our neurosurgical practice was completely modified. For example, we also evaluated the rate of aneurysmal subarachnoid haemorrhages (SAH) and ruptured arteriovenous malformations admitted during the containment period, and we demonstrated a dramatic decrease in the number of patients admitted for these pathologies [2]. Another study [6] focused on neuroemergencies in Berlin during the COVID pandemic. The authors compared all admissions for neuro-emergencies in their department from February to April in 2020 to the same period in 2019 and found a decrease of $46 \%$ of admissions. Finally, it is clear that we had less COVID patients in Normandy than in several areas all around the world, including Lombardy, where our neurosurgeon's colleagues had to take care of COVID patients [33].

\section{Modification of the aetiologies of TBI}

The French population have relatively respected the containment governmental rules which have led to a major decrease in the use of the car, bike, or other individuals' way of moving. Therefore, in our study, the rate of severe TBI related to traffic road injury admitted during the containment period has decreased. This is in line with the data provided by the French Security Road Agency [15] which has reported a diminution of the frequency of traffic road accidents by $74 \%$ and a decrease of the death related to these accidents of $55.8 \%$ in April 2020 as compared to April 2019. The sex ratio radically changed with the containment $(0.21$ women vs 0.45 during the containment). Indeed, the drop in male predominance is maybe linked to the decrease in road traffic accidents. To go on with the aetiology of severe TBI, accidental falls come in first followed by road traffic accidents, during the containment as well as before, which is consistent with the literature $[8,16]$. Other European countries observed the same evolution in TBI mechanisms during lockdown [24]. On the one hand, the containment related to the COVID-19 pandemic has had a positive effect, by decreasing the rate of severe TBI related to traffic road accidents. On the other hand, the containment has increased in absolute value the rate of domestic accident. We noticed a rise of severe TBI linked to alcohol consumption, or long-term alcohol abuse, which is a risk factor of TBI [21], and particularly of acute SDH [28]. Rolland et al. [22] evaluated the substance's use, including alcohol, during the lockdown. They pointed out daily consumption of $57 \%$ in the adult population during containment, namely an increase of $23 \%$, related to the increase of the prevalence of depressive and anxiety symptoms [18]. Also, the sex ratio was clearly modified, with an increase in the rate of women admitted for severe TBI during the containment period. It raises the question of the psychological impact of the containment, which may have led to an increase of massive alcohol consumption at home, and to domestic violence, particularly against women.

We have highlighted the increased rate of SDH evacuation in the lockdown cohort. Surgical indications for acute SDH's evacuation were based on clinical and radiological factors according to previous studies [25]. This difference raised questions, and we have subsequently compared this subgroup of patients before and during the containment (Table 3). We did not notice any statistically significant differences. This suggests no impact of ethical considerations in this difference. This increase in the number of SDH is probably related to the change of TBI's mechanisms and the implication of alcohol, as previously discussed.

\section{COVID management in ICU, ethical considerations, and lessons for the future}

Our two hospitals were reorganized to admit the COVID patients in the dedicated units, for conventional hospitalization as well as for ICU. At Caen Hospital, the neuro ICU continued to admit only brain-injured patients. At Rouen Hospital, a part of the neuro ICU became a versatile surgical ICU. But overall, no patient with the COVID was voluntarily admitted to neurointensive care. To avoid COVID-19 contamination of the patients admitted in the neuro-ICU, every patient was tested with a nasal swab at admission, and every time they had symptoms.

We must keep in mind that ethical considerations could be involved in the variations here reported in terms of incidence, typology, and prognostic of traumatic brain injury during the containment. The COVID-19 pandemic put health systems to the test all over the world, creating an unseen tension in exposed countries between resources on one hand and the explosion of the needs. The consequences of this situation could be observed at two levels in the management of brain-injured patients at the acute and subacute phases. First, critical careand then tertiary care centre - admission triage rules could be a shift from a liberal policy (admitting any critically ill patient independently of any other consideration) to a more restrictive strategy, establishing a hierarchy between patients for hospital admission with prioritization of ethical principle values: maximization of the benefits, favouring of the worst-off, promotion of instrumental value [7]. Then, end-of-life policies could be impacted by the change in the application of distributive justice, one of the four keys of the medical ethics of Beauchamp and Childress [1]. This can be challenged by a shortage in healthcare resources. A more intensely application of distributive justice could lead to an increase of withdrawal of therapeutics in poor prognostic patients and subsequently 
with increased mortality. However, these two hypotheses seem unlikely since (1) Normandy health system was not overwhelmed by COVID-19 and other critically ill patients with critical care occupancy rate $<100 \%$ at the peak of the surge in contrast with 144-233\% rates observed in the Paris region or in the eastern French regions [26], and (2) mortality was decreased during the containment.

At the time of article submission, our region, as for many areas in the world, continues to fight against the virus. We had a second wave in November 2020, which had led to a new containment period of 6 weeks. We are now at the third wave, and a curfew at $6 \mathrm{pm}$ was established all over France this winter. Concerning the rate of severe TBI, the new containment, as well as the curfew, seem to lead to similar observations: a decrease in the number and severity of severe TBI. This is probably related to a diminution of road traffic accidents, mainly occurring during the night and after massive alcohol consumption.

\section{Limits}

We must underline the limitations of the present study. First, the retrospective design of the study, which could have led to bias. Secondly is the fact that we only evaluated short-term outcomes and, moreover, that we have not evaluated functional outcomes. Third, we are aware that the number of patients admitted during the containment period is rather low, which could decrease the robustness of the statistical analysis. Moreover, some patients could have been transferred to other centres. However, it seems unlikely for two reasons: (1) the neurosurgical system of care is clearly defined in France, and in the case of emergency, patients from a geographic area are always referred to the same centre. (2) Normandy was notably less affected by the outbreak of COVID-19 than other French regions and no patient was transferred out of the region during the lockdown.

\section{Conclusion}

To conclude, the French population respected the governmental rules and the containment saved many lives by limiting the number of fatal cases related to COVID-19 infection [23], but also in a more marginal way by modifying the frequency and severity of TBI. This drop in the number of TBI had also another benefit: limiting the number of patients admitted to intensive care units for TBI, which has freed some places for COVID-19 patients.

\section{Declarations}

Ethical approval All procedures performed in studies involving human participants were in accordance with the ethical standards of the institutional Ethics Committee of Caen University Hospital (Caen, France) and with the 1964 Helsinki declaration and its later amendments or comparable ethical standards.

Formal consent For this type of study, formal consent is not required.

Conflict of interest The authors declare no competing interests.

\section{References}

1. Beauchamp TL, Childress JF (2001) Principles of biomedical ethics, 5th edn. Oxford University Press, New York

2. Bernat AL, Gaberel T, Giammattei L, Rault F, Gakuba C, Magro E, Peltier C, Graillon T, Baussart B, Premat K, Clarençon F, Nouet A, Civelli F, Froelich S (2020) Intracranial hemorrhage related to brain vascular disease and COVID-19 containment: where are the patients? Neurochirurgie. https://doi.org/10.1016/j.neuchi.2020.06. 127

3. Borsa S, Bertani G, Pluderi M, Locatelli M (2020) Our darkest hours (being neurosurgeons during the COVID-19 war). Acta Neurochir 162(6):1227-1228

4. Chibbaro S, Ganau M, Todeschi J, Proust F, Cebula H (2020) How SARS-CoV-2 is forcing us to reconsider and reorganize our daily neurosurgical practice. Neurochirurgie 66(4):189-191. https://doi. org/10.1016/j.neuchi.2020.05.001

5. Figueroa JM, Boddu J, Kader M, Berry K, Kumar V, Ayala V, Vanni S, Jagid J (2021) The effects of lockdown during the severe acute respiratory syndrome coronavirus 2 (SARS-CoV-2) pandemic on neurotrauma-related hospital admissions. World Neurosurg 146:e1-e5

6. Hecht N, Wessels L, Werft FO, Schneider UC, Czabanka M, Vajkoczy P (2020) Need for ensuring care for neuroemergencies-lessons learned from the COVID-19 pandemic. Acta Neurochir 162(8):1795-1801

7. Hulsbergen AFC, Eijkholt MM, Balak N, Brennum J, Bolger C, Bohrer AM, Feldman Z, Holsgrove D, Kitchen N, Mathiesen TI, Moojen WA, Samprón N, Sames M, Sandvik U, Tisell M, Broekman MLD (2020) Ethical triage during the COVID-19 pandemic: a toolkit for neurosurgical resource allocation. Acta Neurochir 162(7):1485-1490

8. Iaccarino C, Carretta A, Nicolosi F, Morselli C (2018) Epidemiology of severe traumatic brain injury. J Neurosurg Sci 62(5):535-541

9. Jayakumar N, Kennion O, Villabona AR, Paranathala M, Holliman D (2020) Neurosurgical referral patterns during the coronavirus disease 2019 pandemic: a United Kingdom experience. World Neurosurg 144:e414-e420

10. Jean WC, Ironside NT, Sack KD, Felbaum DR, Syed HR (2020) The impact of COVID-19 on neurosurgeons and the strategy for triaging non-emergent operations: a global neurosurgery study. Acta Neurochir 162(6):1229-1240

11. Luostarinen T, Virta I, Satopää J, Bäcklund M, Kivisaari R, Korja M, Raj R (2020) Intensive care of traumatic brain injury and aneurysmal subarachnoid hemorrhage in Helsinki during the Covid-19 pandemic. Acta Neurochir 162(11):2715-2724

12. Marshall LF, Marshall SB, Klauber MR, Van Berkum CM, Eisenberg H, Jane JA, Luerssen TG, Marmarou A, Foulkes MA (1992) The diagnosis of head injury requires a classification based on computed axial tomography. J Neurotrauma Suppl:S287-S292

13. Mathé JF, Richard I, Rome J (2005a) Santé publique et traumatismes crâniens graves. Aspects épidémiologiques et financiers, structures et filières de soins. Annales Françaises 
d'Anesthésie et de Réanimation 24(6):688-694. https://doi.org/10. 1016/j.annfar.2005.03.029

14. Mathiesen T, Arraez M, Asser T, Balak N, Barazi S, Bernucci C, Bolger C, Broekman MLD, Demetriades AK, Feldman Z, Fontanella MM, Foroglou N, Lafuente J, Maier AD, Meyer B, Niemelä M, Roche PH, Sala F, Samprón N, Sandvik U, Schaller $\mathrm{K}$, Thome C, Thys M, Tisell M, Vajkoczy P, Visocchi M, and on behalf of the EANS (2020) A snapshot of European neurosurgery Decembre 2019 vs. March 2020: just before and during the Covid19 pandemic. Acta Neurochir 162(9):2221-2233

15. Observatoire national interministériel de la sécurité routière $(2020$, May 15) Baromètre avril 2020. https://www.onisr.securite-routiere. gouv.fr/etat-de-1-insecurite-routiere/suivis-mensuels-et-analysestrimestrielles/barometre-mensuel-en-metropole-et-outre-mer/ barometre-avril-2020

16. Peeters W, van den Brande R, Polinder S, Brazinova A, Steyerberg EW, Lingsma HF, Maas AI (2015) Epidemiology of traumatic brain injury in Europe. Acta Neurochir 157(10):1683-1696

17. Pichard R, Kopel L, Lejeune Q, Masmoudi R, Masmejean EH (2020) Impact of the COronaVIrus Disease 2019 lockdown on hand and upper limb emergencies: experience of a referred university trauma hand centre in Paris, France. Int Orthop 44(8):14971501. https://doi.org/10.1007/s00264-020-04654-2

18. Pieh C, Budimir S, Delgadillo J, Barkham M, Fontaine JRJ, Probst T (2020) Mental health during COVID-19 lockdown in the United Kingdom. Psychosom Med. https://doi.org/10.1097/psy. 0000000000000871

19. Pinggera D, Klein B, Thome C, Grassner L (2020) The influence of the COVID-19 pandemic on traumatic brain injuries in Tyrol: experiences from a state under lockdown. Eur J Trauma Emerg Surg. https://doi.org/10.1007/s00068-020-01445-7

20. Poupet C, Roger P (2020) Bilan démographique 2019 : la population normande poursuit sa baisse. https://www.insee.fr/fr/ statistiques/4652181\#: :text=Au\%201er\%20janvier\%202020\% 2C\%203\%20303\%20500\%20habitants\%20r\%C3\%A9sident,de\% 20Loire\%20et\%201a\%20Corse

21. Pöyry T, Luoto TM, Kataja A, Brander A, Tenovuo O, Iverson GL, Ohman J (2013) Acute Assessment of Brain Injuries in GroundLevel Falls. J Head Trauma Rehabil 28(2):89-97

22. Rolland B, Haesebaert F, Zante E, Benyamina A, Haesebaert J, Franck N (2020) Global changes and factors of increase in caloric food, screen and substance use during the early COVID-19 containment phase in France: a general population online survey. JMIR Public Health Surveill 6(3):e19630
23. Salzberger B, Glück T, Ehrenstein B (2020) Successful containment of COVID-19: the WHO-report on the COVID-19 outbreak in China. Infection 48(2):151-153

24. Servadei F, Cannizzaro D (2021) Effects on traumatic brain injured patients of COVID pandemia: which responses from neurosurgical departments? Acta Neurochir. https://doi.org/10.1007/s00701-02104724-3

25. Servadei F (1997) Prognostic factors in severely head injured adult patients with acute subdural haematoma's. Acta Neurochir 139(4): 279-285

26. Santé publique France (2020 April 30) COVID-19 Point épidémiologique hebdomadaire du 30 avril 2020 https://www. santepubliquefrance.fr/content/download/249184/2589560

27. Santé publique France (2020 May 14) COVID-19 Point épidémiologique hebdomadaire du 14 mai $2020 \mathrm{https} / / \mathrm{www}$. santepubliquefrance.fr/content/download/252588/2603686

28. Sonne NM, Tønnesen H (1992) The influence of alcoholism on outcome after evacuation of subdural haematoma. Br J Neurosurg 6(2): $125-130$

29. Steyerberg EW, Mushkudiani N, Perel P, Butcher I, Lu J, McHugh GS, Murray GD, Marmarou A, Roberts I, Habbema JDF, Maas AIR (2008) Predicting outcome after traumatic brain injury: development and international validation of prognostic scores based on admission characteristics. PLoS Med 5(8):e165. https://doi.org/10. 1371/journal.pmed.0050165

30. Venter A, Lewis CM, Saffy P, Chadinha LP (2020) Locked down: Impact of COVID-19 restrictions on trauma presentations to the emergency department. S Afr Med J 111(1):52-56

31. World Health Organization (2020 April 4) Coronavirus disease 2019 (COVID-19) Situation Report - 75. https://www.who.int/ docs/default-source/coronaviruse/situation-reports/20200404sitrep-75-covid-19.pdf?sfvrsn=99251b2b_4

32. Wu Z, McGoogan JM (2020) Characteristics of and important lessons from the coronavirus disease 2019 (COVID-19) outbreak in China: summary of a report of 72314 cases from the Chinese Center for Disease Control and Prevention. JAMA 323(13):12391242

33. Zoia C, Bongetta D, Veiceschi P, Cenzato M, Di Meco F, Locatelli D, Boeris D, Fontanella MM (2020) Neurosurgery during the COVID-19 pandemic: update from Lombardy, northern Italy. Acta Neurochir 162(6):1221-1222. https://doi.org/10.1007/ s00701-020-04305-w

Publisher's note Springer Nature remains neutral with regard to jurisdictional claims in published maps and institutional affiliations. 